Original Artical

\title{
Cephalometric Norms for Orthognathic Surgery in Kerala Population
}

\author{
M urali Patla ${ }^{1}$, Sonika Achalli ${ }^{2}$, K. Saidath ${ }^{3}$, Crystal Runa Soans ${ }^{4}$, U.S. Krishna Nayak ${ }^{5}$ \\ ${ }^{1,2,4}{ }_{\text {Lecturer, }}{ }^{3}$ Professor, ${ }^{5}$ Principal and Dean, Professor, ${ }^{1,3,4,5}$ Department of Orthodontics and Dentofacial Orthopaedics, \\ ${ }^{2}$ Department of Oral Medicine and Radiology, A.B. Shetty Memorial Institute of Dental Sciences, NITTE University, \\ Deralakatte, M angalore - 575018. \\ *Corresponding Author: M urali Patla, Lecturer, Department of Orthodontics and Dentofacial Orthopaedics, A.B. Shetty Memorial \\ Institute of Dental Sciences, NITTE University, Mangalore, M obile : +919746344566, E-mail : drmuralips@gmail.com.
}

Received

: 26.10 .2016

Review Completed : 01.01.2017

Accepted

02.02.2017

Keywords : Cephalometric, Keralites, Orthognathic surgery, COGSAnalysis

\begin{tabular}{|c|}
\hline Access this article online \\
\hline Quick Response Code \\
\hline
\end{tabular}

\section{Abstract}

Background and objectives: The successful treatment of orthognathic surgical patient is dependent on careful diagnosis. The first step in the diagnosis of the patient for orthognathic surgery is to determine the nature of the skeletal, dental and soft tissue defects. Cephalometrics for orthognathic surgery (COGS) analysis by Burstone and colleagues is especially adapted for the diagnosis and treatment planning of orthognathic surgery cases. Burstone and colleagues COGS analysis are based on Caucasian whites; they may not be applicable as a reference for the diagnosis and treatment of Kerala population patients. Therefore it has become important to determine the cephalometric parameters for this ethnic group.

Methodology : Cephalometric radiographs of 50 Keralite adults ( $25 \mathrm{M}$ ales and 25 Females) were analysed who met criteria of the study. The Mean values of various skeletal, dental, angular and linear measurements of Keralites were compared with the White Americans values, originally obtained by Burstone.

Results : Statistically significant differences were found in the Keralite samples, who had a greater Anterior and Posterior Cranial base length, Mandibular protrusion, Lower anterior facial heights, Anterior and Posterior Dental heights, Proclined Upper and Lower incisor with less Prominent Chin in comparison to Caucasian.

Interpretation and conclusion : This is indicative of disparity between cephalometric norms of Caucasians and Keralites. However conclusions can't be drawn from a single study, hence further studies to establish the cephalometric norms for different ethnic groups across the country may be advisable.

\section{Introduction}

An esthetically pleasing face with smile is a key determinant of successful orthographic surgical and orthodontic treatment. Every person's face is a custom made original. The unique facial characteristic of each individual depends on topographic location, racial, ethnic background and heredity.

The research in the last two decades by Cotton, Takano and Wong ${ }^{[1]}$, Harala-bakis ${ }^{[2]}$, Altemus ${ }^{[3]}$, and Kotak ${ }^{[4]}$ has indicated that normal measurements of one racial group cannot be considered normal for some other racial groups. So the knowledge of normal dentofacial pattern of adults belonging to various ethnic groups is important to determine the nature of skeletal, dental and soft tissue defect for clinical and research purposes. Thus different racial groups will have to be treated according to their own individual facial features.

Since the advent of roentgenographic cephalometry, several analyses ${ }^{[5,6,7,8,9]}$ have been put forward by various research workers. All of these analyses presented average measurements of skeletal and/or dental patterns with their ranges in a sample. It was recommended that after treatment a case should attain maximum number of normal mean measurements. 
The successful treatment of orthognathic surgical patient is dependent on careful diagnosis. The first step in the diagnosis of the orthognathic surgical patient is to determine the nature of the skeletal, dental and soft tissue defects. Cephalometrics for orthognathic surgery (COGS) analysis by Burrstone and colleagues is especially adapted for the diagnosis and treatment planning of orthognathic surgery cases for Caucasian whites. ${ }^{[10,11]}$

Burrstone and colleagues COGS analysis ${ }^{[10,11]}$ is based on Caucasian whites; they may not be applicable as a reference for the Diagnosis and Treatment of Kerala population patients. Therefore it has become important to determine the cephalometric parameters for this ethnic group.

The study was conducted with the following aims and objectives:

1. To establish Skeletal and Dental norms (COGS) for Kerala population.

2. To compare the values with that of Caucasian standards.

\section{Methodology}

\section{Materials and Methods}

The records comprising of lateral cephalograms were obtained from the Kerala adult patients visiting the outpatient department. Sample constituted of 50 Kerala individuals of which 25 males and 25 females with age ranging from 18 to 30 years were enrolled for the study.

The subjects were selected with class I molar relationship with minimum or no crowding, straight facial profile, with the presence of all the teeth anterior to the second molar.

Subjects with facial asymmetry determined clinically and radiographically, and who had undergone orthodontic or orthognathic surgical treatments were excluded from the study.

All lateral cephalometric radiographs were taken in a standardized manner in centric occlusion with lips in repose and the FH plane oriented horizontally according to the natural head position after obtaining the patient consent. The cephalometric landmarks were identified according to the definitions used by Burstone, then angular and linear measurement[fig1-5] was taken after tracing using 0.003 " thick matte finish acetate sheet [fig 6-7]

\section{Statistical Analysis}

All the readings obtained were subjected to statistical analysis. M ean, standard deviations were determined for male and female groups and compared with Burstone's norms. Data obtained were analysed using Statistical Package for Social Sciences (Windows version 17.0, SPSS Inc., Chicago, Illinosis, USA). Student unpaired t-test was used to assess difference.

$$
\begin{aligned}
& t=\frac{(X 1-X 2)}{S E} \\
& X_{1}=M \text { ean of study group } \\
& X_{2}=M \text { ean of standard group } \\
& \text { S.E }=\text { standard error }
\end{aligned}
$$$$
\mathrm{SE}=\text { Standard error }
$$$$
\mathrm{SE}=\sqrt{\frac{\left(\sigma_{1}^{2}+\sigma_{2}^{2}\right)}{\mathrm{n}}}
$$$$
\sigma_{1}=S D \text { of Kerala group }
$$$$
\sigma_{2}=S D \text { of Caucasian group }
$$$$
\mathrm{n}=\text { Number of sample }
$$

\section{Result}

Various angular and linear measurements for skeletal and dental tissue in both males and females of Kerala population were obtained and were tabulated [tab.1\&2]. All obtained readings were subjected to statistical analysis. M ean, standard deviations were determined for the total sample, male and female groups. The mean and standard deviations of each group and the values originally obtained by Burstone were compared [tab.1\&2]. Significance was determined at 0.05 levels of confidence.

When comparing Kerala males with Caucasian males, statistically significant difference was found in the mean values of the both skeletal and dental parameters, such as PTM -N (II HP),Ar-PtM (II HP) 1-NF (angle), B-Pg (II MP),N-B (II HP) which are represented in Table-1. When comparing Kerala females with Caucasian females, the study revealed statistically significant difference between the mean values of the both skeletal and dental parameters, such as Ar-PtM (II HP), PTM-N (II HP), B-Pg (II MP), N-Pg (IIHP), ANSGn(IIHP), PNS-N (I HP), 1-NF ( I NF), 1-MP ( I MP), 6-NF (I NF)PNS-ANS (IIHP), N-B (II HP) which are represented in Table-2. 


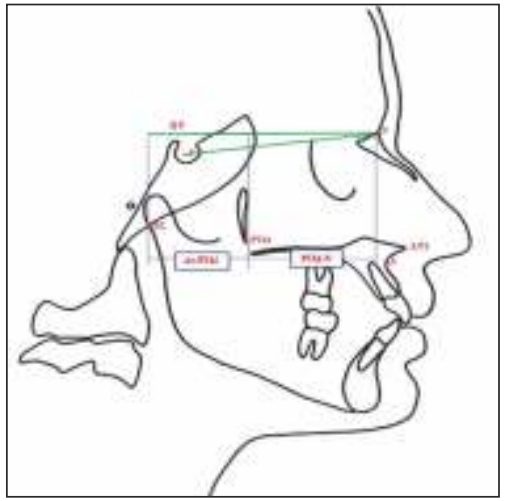

Fig. 1 : Cranial base-Linear measurements 1. Anterior cranial base (Ar-PTM)

2. Posterior cranial base (PTM-N)

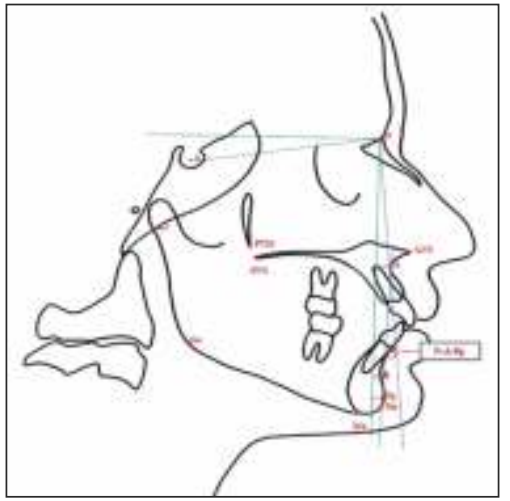

Fig. 2 : Horizontal skeletal - linear and angular Measurements

1. Facial convexity (N-A-Pg)

2. Maxillary protrusion (N-A)

3. M andibular protrusion (N-B)

4. Chin protrusion (N-Pg)

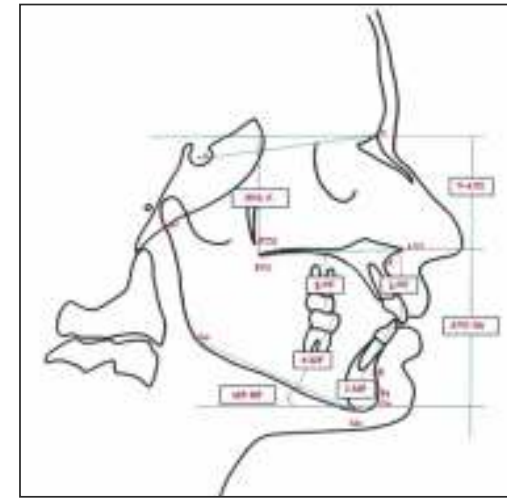

Fig. 3 : Vertical skeletal and dental linear and angular measurements 1. Upper anterior facial height (N-ANS)

2. Lower anterior facial height (ANS-Gn)

3. Upper posterior facial height( PNS-N)

4. Mandibular plane angle (MP-HP)

5. Upper anterior Dental height (1-NF)

6. Upper posterior Dental height (-NF)

7. Lower anterior Dental height (1-MP)

8. Lower posterior Dental height (6-MP)

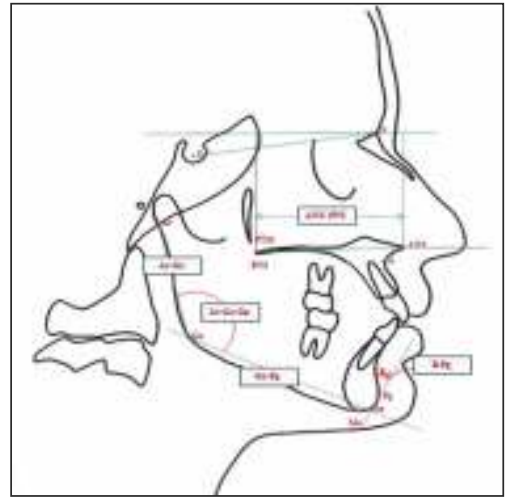

Fig. 4 : M axillary and M andibular linear and angular measurements 1. M axillary length (PNS-ANS)

2. Mandibular body length (Ar-Go)

3. M andibular ramus length (Go-Pog)

4. Chin depth (B-Pog)

5. Gonial angle (Ar-Go-Gn)

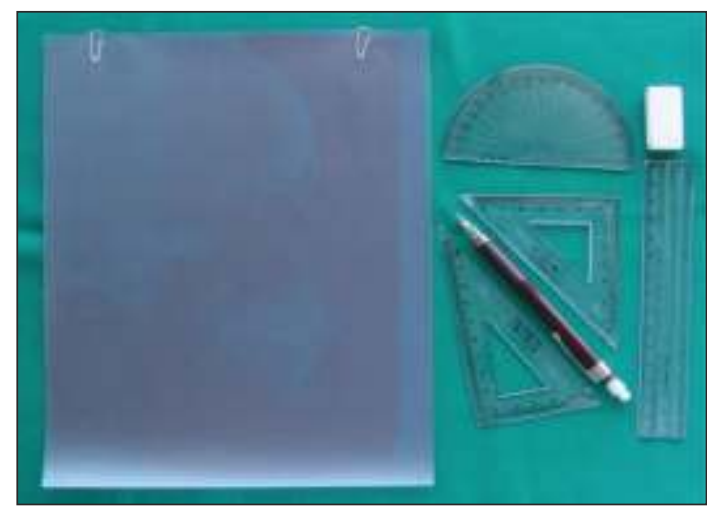

Fig. 6 : Armamentarium used for the study

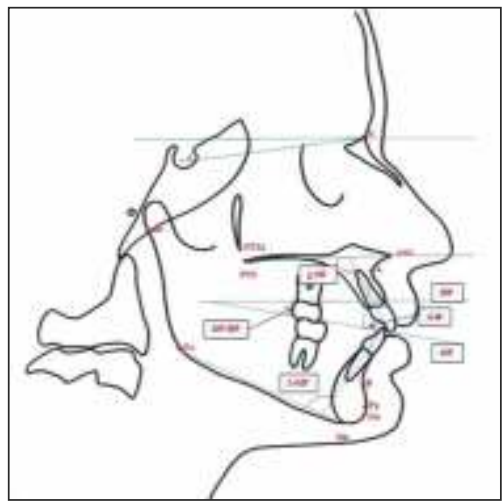

Fig. 5 : Dental linear and angular measurements

1. Occlusal plane angle (OP-HP)

2. Wits analysis (A-B)

3. Upper incisor inclination (1-NF)

4. Lower incisor inclination(1-MP)

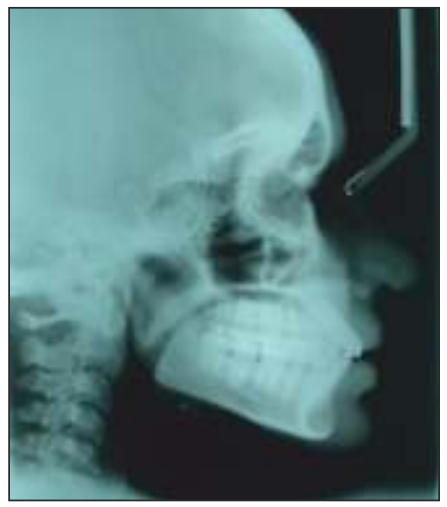

Fig. 7 : Standard cephalogram of the Kerala subject 
Table 1 : Comparison of Orthognathic Cephalometric Analysis M easurement of Hard Tissue between Kerala M ale and Caucasian Male

$\mathrm{N}=25$

\begin{tabular}{|c|c|c|c|c|c|c|}
\hline \multirow[t]{2}{*}{ Measurement } & \multicolumn{2}{|c|}{ KERALA M ALE } & \multicolumn{2}{|c|}{ CAUCASIAN MALE } & \multirow[t]{2}{*}{ t- value } & \multirow[t]{2}{*}{$P$-value } \\
\hline & $\begin{array}{l}\text { M ean } \\
\text { (Male) }\end{array}$ & $\begin{array}{l}\text { Standard } \\
\text { deviation }\end{array}$ & $\begin{array}{l}\text { M ean } \\
\text { (Male) }\end{array}$ & $\begin{array}{l}\text { Standard } \\
\text { deviation }\end{array}$ & & \\
\hline \multicolumn{7}{|l|}{ Cranial Base } \\
\hline Ar-PtM (II HP) & 41.1300 & 4.6700 & 37.1000 & 2.80000 & 2.9370 & 0.001 \\
\hline PTM-N (II HP) & 57.1400 & 3.4500 & 52.8000 & 4.10000 & 3.551 & 0.001 \\
\hline \multicolumn{7}{|c|}{ Horizontal (skeletal) } \\
\hline $\mathrm{N}-\mathrm{A}-\mathrm{Pg}$ (angle) & 1.5200 & 3.59537 & 3.9000 & 6.40000 & 1.66200 & 0.103 \\
\hline $\mathrm{N}-\mathrm{A}(\mathrm{II} \mathrm{HP})$ & -.4400 & 2.46357 & .0000 & 3.70000 & .49500 & 0.629 \\
\hline $\mathrm{N}-\mathrm{B}(\mathrm{II} \mathrm{HP})$ & .0200 & 5.49902 & -5.3000 & 6.70000 & 3.98300 & $<.001$ \\
\hline $\mathrm{N}-\mathrm{Pg}(\mathrm{II} \mathrm{HP})$ & 1.4800 & 4.63339 & -4.3000 & 8.50000 & 1.45800 & 0.152 \\
\hline \multicolumn{7}{|c|}{ Vertical (skeletal, dental) } \\
\hline N-ANS (I HP) & 55.7000 & 3.46109 & 54.7000 & 3.20000 & 1.06000 & 0.74 \\
\hline ANS-Gn (IIHP) & 68.4400 & 2.86255 & 68.6000 & 3.80000 & .00000 & 1 \\
\hline PNS-N (I HP) & 54.8000 & 3.26917 & 53.9000 & 1.70000 & 1.87000 & 0.067 \\
\hline MP-HP (angle) & 22.0000 & 3.59398 & 23.0000 & 5.90000 & .72300 & 0.472 \\
\hline 1-NF ( I NF) & 30.0200 & 2.60800 & 30.5000 & 2.10000 & .71200 & 0.476 \\
\hline 1-MP (I MP) & 43.7200 & 3.20507 & 45.0000 & 2.10000 & 1.69800 & 0.095 \\
\hline$\underline{6}-\mathrm{NF}$ (I NF) & 26.0800 & 2.25315 & 26.0000 & 2.00000 & .14400 & 0.885 \\
\hline 6-MP (I MP) & 34.1600 & 3.46627 & 35.8000 & 2.60000 & 1.89200 & 0.065 \\
\hline \multicolumn{7}{|l|}{ Maxilla, Mandible } \\
\hline PNS-ANS (IIHP) & 57.1000 & 3.66003 & 57.7000 & 2.50000 & .67600 & 0.502 \\
\hline Ar-Go (linear) & 53.2000 & 3.12583 & 52.0000 & 4.20000 & 1.14600 & 0.257 \\
\hline Go-Pg (linear) & 81.4400 & 4.77694 & 83.7000 & 4.60000 & 1.90400 & 0.095 \\
\hline $\mathrm{B}-\mathrm{Pg}(\mathrm{II} \mathrm{M}$ P) & 5.7600 & 4.70841 & 8.9000 & 1.70000 & 3.13600 & 0.0029 \\
\hline Ar-Go-Gn (angle) & 121.6400 & 4.90646 & 119.1000 & 6.60000 & 1.54100 & 0.129 \\
\hline \multicolumn{7}{|l|}{ Dental } \\
\hline $\mathrm{OP}$ - HP (angle) & 5.2520 & 3.72549 & 6.2000 & 5.10000 & .75100 & 0.456 \\
\hline$A-B(\| \mathrm{OP})$ & -.7800 & 1.80324 & -1.1000 & 2.00000 & .59400 & 0.55 \\
\hline 1-NF (angle) & 116.7600 & 5.26213 & 111.0000 & 4.70000 & 4.08100 & 0.001 \\
\hline 1-M P (angle) & 93.4600 & 2.63670 & 95.9000 & 5.20000 & .53900 & 0.595 \\
\hline
\end{tabular}

Table 2 : Comparison of Orthognathic Cephalometric Analysis Measurement of Hard Tissue between Kerala Female and Caucasian Female

$\mathrm{N}=25$

\begin{tabular}{|c|c|c|c|c|c|c|}
\hline \multirow[t]{2}{*}{ M easurement } & \multicolumn{2}{|c|}{ KERALA FEM ALE } & \multicolumn{2}{|c|}{ CAUCASIAN FEM ALE } & \multirow[t]{2}{*}{ t- value } & \multirow[t]{2}{*}{$\mathrm{P}$-value } \\
\hline & $\begin{array}{c}\text { Mean } \\
\text { (Female) }\end{array}$ & $\begin{array}{l}\text { Standard } \\
\text { deviation }\end{array}$ & $\begin{array}{c}\text { Mean } \\
\text { (Female) }\end{array}$ & $\begin{array}{l}\text { Standard } \\
\text { deviation }\end{array}$ & & \\
\hline \multicolumn{7}{|l|}{ Cranial Base } \\
\hline Ar-PtM (II HP) & 38.7200 & 1.8559 & 32.1000 & 1.90000 & 5.9200 & $<0.01$ \\
\hline PTM-N (II HP) & 55.3400 & 3.1391 & 50.9000 & 3.00000 & 4.5000 & $<0.01$ \\
\hline \multicolumn{7}{|c|}{ Horizontal (skeletal) } \\
\hline N-A-Pg (angle) & 4.5000 & 9.27362 & 2.6000 & 5.10000 & .89700 & 0.3731 \\
\hline $\mathrm{N}-\mathrm{A}(\mathrm{II} \mathrm{HP})$ & -.6000 & 2.58602 & -2.0000 & 3.70000 & 1.55000 & 0.128 \\
\hline N-B (II HP) & -1.6000 & 5.79511 & -6.9000 & 4.30000 & 5.12300 & $<.001$ \\
\hline $\mathrm{N}-\mathrm{Pg}$ (II HP) & -.7200 & 5.95658 & -6.5000 & 5.10000 & 3.70800 & $<001$ \\
\hline \multicolumn{7}{|c|}{ Vertical (skeletal, dental) } \\
\hline N-ANS (I HP) & 53.4600 & 2.95776 & 50.0000 & 2.40000 & 1.84100 & 0.0717 \\
\hline ANS-Gn( IHP) & 66.0800 & 4.36052 & 61.3000 & 3.30000 & 4.01000 & 0.001 \\
\hline PNS-N (I HP) & 54.0000 & 3.04822 & 50.6000 & 3.20069 & 4.49500 & 0.001 \\
\hline MP-HP (angle) & 23.4400 & 3.67797 & 24.2000 & 5.00000 & .61200 & .542 \\
\hline 1-NF ( I NF) & 29.0000 & 3.33229 & 27.5000 & 1.70000 & 2.06000 & 0.050 \\
\hline 1-MP (I MP) & 39.5600 & 2.62726 & 40.8000 & 1.80000 & 1.95000 & 0.057 \\
\hline
\end{tabular}




\begin{tabular}{|c|c|c|c|c|c|c|}
\hline \multirow[t]{2}{*}{ M easurement } & \multicolumn{2}{|c|}{ KERALA FEM ALE } & \multicolumn{2}{|c|}{ CAUCASIAN FEMALE } & \multirow[t]{2}{*}{ t- value } & \multirow[t]{2}{*}{$P$-value } \\
\hline & $\begin{array}{c}\text { Mean } \\
\text { (Female) }\end{array}$ & $\begin{array}{l}\text { Standard } \\
\text { deviation }\end{array}$ & $\begin{array}{c}\text { Mean } \\
\text { (Female) }\end{array}$ & $\begin{array}{l}\text { Standard } \\
\text { deviation }\end{array}$ & & \\
\hline$\underline{6}-\mathrm{NF}$ (I NF) & 24.4200 & 2.18746 & 23.0000 & 1.30000 & 2.79000 & 0.0075 \\
\hline 6-MP (I MP) & 31.0000 & 2.95804 & 32.1000 & 1.90000 & 1.56000 & 0.1286 \\
\hline \multicolumn{7}{|l|}{ Maxilla, Mandible } \\
\hline PNS-ANS (IIHP) & 54.8600 & 2.53936 & 52.6000 & 3.50000 & 2.60000 & 0.0119 \\
\hline Ar-Go (linear) & 47.6200 & 2.63106 & 46.8000 & 2.50000 & 1.12900 & 0.264 \\
\hline Go-Pg (linear) & 75.9600 & 5.14158 & 74.3000 & 5.80000 & 1.07000 & 0.284 \\
\hline B-Pg (II M P) & 4.4800 & 3.84187 & 7.2000 & 1.90000 & 3.17400 & $<001$ \\
\hline Ar-Go-Gn (angle) & 123.220 & 3.57095 & 122.0000 & 6.90000 & .78500 & 0.432 \\
\hline \multicolumn{7}{|l|}{ Dental } \\
\hline $\mathrm{OP}$ - HP (angle) & 7.5200 & 2.74044 & 7.1000 & 2.50000 & .56600 & 0.573 \\
\hline$A-B(\| \mathrm{OP})$ & -.0880 & 2.27162 & -.4000 & 2.50000 & .72200 & 0.476 \\
\hline 1-NF (angle) & 113.800 & 5.36190 & 112.5000 & 5.30000 & .86200 & 0.392 \\
\hline 1-MP (angle) & 99.2400 & 8.22233 & 95.9000 & 5.70000 & 1.06600 & 0.101 \\
\hline
\end{tabular}

\section{Discussion}

Broadbent introduced cephalometric radiograph as an orthodontic tool to study craniofacial growth and development, facial forms, development of norms, and growth prediction for the individual patients.

Prime objectives of orthognathic surgery are improvement in the appearance and functions of the dentofacial structures. Patients who need orthognathic surgery usually present with a variation in facial skeletal bone as well as tooth position that must be modified by a combined orthodontic surgical treatment. Therefore a particular cephalometric appraisal system should be incorporated into treatment planning.

Various cephalometric analyses are put forward by various authors. Those that gained importance in orthognathic surgery is Burstone's Cephalometric analysis. ${ }^{[10,11]}$ These were originated by Caucasians for their ethnic groups. The problems encountered during evaluation of potential surgical cases for Kerala population were types of analyses used, and the use of Caucasian standards. M easurement of different analysis done for the Indian population have been different from standards for Caucasians. ${ }^{[2,12,]}$ The cephalometric norms for different Indian ethnic groups have shown marked differences. ${ }^{[13]}$

This study showed significant differences in the Ar-PTM and PTM-N between the races. The Ar-PTM for Kerala males and females was slightly larger than the Caucasian males and females. Also the posterior cranial base measurement was larger in Kerala population compared to Caucasian population with the reading statistically significant. This is similar to the results observed in a comparison study between Black American adults and white American adults by Flynn T.R. et al. ${ }^{[14]}$

In Horizontal skeletal relations angle of convexity (N-A-Pg) was found to be less in Kerala males than Caucasian males. Whereas in Kerala Females these values were more than Caucasians Females, similar to the study done by Rafael $\mathrm{E}$. Alcaide et al ${ }^{[15]}$ and Flynn T.R. et al. ${ }^{[14]}$

Maxillary protrusion ( $\mathrm{N}-\mathrm{A}$ ) was found to be less in both Kerala males and females than Caucasians with the reading statistically not significant.This is similar to the study done by Rafael E. Alcaide et al ${ }^{[15]}$ Whereas study conducted by Flynn T.R. et al ${ }^{[14]}$ showed more maxillary protrusion than Caucasian and it was statistically significant.

M andibular protrusion (N-B) was found to be more in both Kerala males and females than Caucasians with the reading statistically significant.This is similar to the study done by Fonesca R. ${ }^{[16]}$ and Flynn T.R. et al. ${ }^{[14]}$

Chin prominence (N-Pg) was found to be more in Kerala males than Caucasian males, whereas in Kerala females these values were more than Caucasians females, with the reading statistically significant, but a study conducted by Rafael E. Alcaide et al ${ }^{[15]}$ showed less chin protrusion than 
Caucasian and it was statistically not significant.

Lower anterior facial height (ANS-Gn) and Upper posterior facial height (PNS-N) was found to be more in Kerala males than Caucasian males which was statistically not significant; Where as in Kerala females these values were more than Caucasians females with the reading statistically significant and it was similar to the study done by Rafael $\mathrm{E}$. Alcaide et $\mathrm{a}^{[15]}$ and Flynn T.R. et al. ${ }^{[14]}$

M axillary incisor to nasal floor (1-NF), mandibular incisor to mandibular plane (1-MP), maxillary molar to nasal floor (ㅁ$N F$ ), was found to be more in Kerala males than Caucasian males, with the readings statistically significant, and it was similar to the study done by Flynn T.R. et al ${ }^{[14]}$ where as in Kerala females these values were found to be statistically significant.

Mandibular molar to mandibular plane (6-M P) was found to be less in both Kerala males and females than Caucasians with the reading statistically not significant, Whereas study conducted by Flynn T.R. et al ${ }^{[14]}$ showed values more than Caucasians and it was statistically significant.

M axillary length (PNS-ANS) was found to be more in Kerala malesthan Caucasian males. In Kerala females these values were more than Caucasians females, with the reading statistically significant, and is similar to the study done by Flynn T.R. et al. ${ }^{[12]} \mathrm{M}$ andibular ramus length (Ar-Go) was found to be more in Kerala males and females than Caucasians with the statistically insignificant readings. This was similar to the study done by Rafael E. Alcaide et al ${ }^{[15]}$ and Flynn T.R. et al. ${ }^{[14]}$

Chin depth (B-Pg) was found to be less in Kerala males and females than Caucasians with statistically significant readings. This was similar to the study done by Rafael $\mathrm{E}$. Alcaide et al ${ }^{[15]}$ and Flynn T.R. et al. ${ }^{[14]}$

Maxillary incisor angulation to the nasal floor (1-NF) was found to be more in Kerala males and females than Caucasians with the statistically significant readings in Kerala males. This was similar to the study done by Rafael $\mathrm{E}$. Alcaide et al ${ }^{[15]}$ and Flynn T.R. et al. ${ }^{[14]}$

This study resembles most of the other study of comparisons of American blacks and whites ${ }^{[12]}$ but, no study has been published for orthognathic norms for Kerala population, whereas a number of studies have been carried out for different analysis.The norms developed in this study describes the average facial feature of that portion of the Kerala population that has an orthognathic and pleasing profile with Angles Class I occlusion without any abnormalities.

\section{Conclusion}

This study compared Kerala population and Caucasian population (Male and Female) for cephalometric differences in skeletal and dental parameters. The result of the study allows the following conclusions.

- There was greater anterior and posterior cranial base length, in Keralites in comparison to Caucasians.

- The study found higher mandibular prognathism and a prominent chin with lesser maxillary protrusion and facial convexity angle in Kerala subjects.

- There were greater upper anterior and posterior facial height, lower anterior facial height, mandibular ramus length, maxillary length and mandibular body length in Keralites; whereas mandibular plane angle and chin depth wasfound be less than Caucasians.

- The study found greater upper and lower dental heights, with proclaimed upper and lower incisor.

This is indicative of disparity between cephalometric norms of Caucasians and Keralites. However conclusions can't be drawn from a single study, hence further studies to establish the cephalometric norms for different ethnic groupsacross the country may be advisable. 


\section{References}

1. Cotton, W. N., Takano, W. S., and Wong, W. W.: The Downs Analysis Applied to Three Other Ethnic Groups. Angle Orthod, 21:213-220, 1951.

2. Haralabakis, H.: Familial Resem-blances in Craniofacial Greek Families. Abst. In A. J. Ortho., 1954.

3. Altemus, L. A. A Comparison of Cephalofacial Relationships. Angle Orthod. 30:223-240, 1960

4. Kotak, V. B, Cephalometric Evaluation of Indian Girls with Neutral Occlusion. J.A.LD.A., 36:183, 1964

5. Margolis, H. L: A Basic Facial Pattern and its Application in Clinical Orthodontics. A. J. Ortho., 33:631-641, 1947,

6. Tweed, C. H.: The Frankfort-Mandibular Incisor Angle (FMIA) in Orthodontic Diagnosis, Treatment Planningl and Prognosis. Angle Orthod, 24:121-169, 1954

7. Downs, W. B.: Variation in Facial Relationships: Their Significance in Treatment and Prognosis. A. J. Ortho., 34:812-840, 1948.

8. Sassouni V.: RoentgenographsCepholametric Analysis of CephaloFacial-Dental Relationships. A. Ortho., 41:735-764, 1955.

9. Coben, S. E.: The Integration of Facial Skeletal Variants. A. J. Ortho.,
41:407-434, 1955

10. Burstone C], James RB, Legan H, et al: Cephalometric for orthognathic surgery. J Oral Surg 36:269, 1978

11. Legan $\mathrm{HL}$, Burstone C): Soft tissue cephalometric analysis for orthognathic surgery.J Oral Surg 38: 744, 1980

12. Nanda R, Nanda RS. Cephalometric study of the dentofacial complex of North Indians. Angle Orthod: 1969; 39; 23-8.

13. Abhilasha O Yadav, Chanjyot Singh Walia, Rajiv M Borle, Kiran H Chaoji, RiteshRajan, Abhay N Datarkar: Cephalometric norms for Central Indian population using Burstone and Legan analysis. Indian Journal of Dental Research, 22(1), 2011

14. Thomas R. Flynn, Riccardo I Ambrogio, and Samuel J. Zeichner, Cephalometric norms for orthognathic surgery in Black American Adults. J Oral M axillfacSurg 47:30-38, 1989

15. Rafael E. Alcalde, Tokiarijinno, M Anthony Pogrel, and Tomohiro Matsumura, Cephalometric norms for Japanese Adult. J Oral MaxillfacSurg 56:129-134,1998

16. Fonesca RJ, Klein WD: A cephalometric evaluation of American Negro women. Am J Orthod 73: 152, 1978 